\title{
Minimum aerosol layer detection sensitivities and their subsequent impacts on aerosol optical thickness retrievals in CALIPSO level 2 data products
}

\author{
Travis D. Toth ${ }^{1}$, James R. Campbell ${ }^{2}$, Jeffrey S. Reid ${ }^{2}$, Jason L. Tackett ${ }^{3}$, Mark A. Vaughan ${ }^{4}$, Jianglong Zhang ${ }^{1}$, and \\ Jared W. Marquis ${ }^{1}$ \\ ${ }^{1}$ Dept. of Atmospheric Sciences, University of North Dakota, Grand Forks, ND, USA \\ ${ }^{2}$ Aerosol and Radiation Sciences Section, Marine Meteorology Division, Naval Research Laboratory, Monterey, CA, USA \\ ${ }^{3}$ Science Systems and Applications, Inc., Hampton, VA, USA \\ ${ }^{4}$ NASA Langley Research Center, Hampton, VA, USA
}

Correspondence: Travis D. Toth (travis.toth@und.edu)

Received: 18 September 2017 - Discussion started: 20 September 2017

Revised: 6 December 2017 - Accepted: 8 December 2017 - Published: 24 January 2018

\begin{abstract}
Due to instrument sensitivities and algorithm detection limits, level 2 (L2) Cloud-Aerosol Lidar with Orthogonal Polarization (CALIOP) $532 \mathrm{~nm}$ aerosol extinction profile retrievals are often populated with retrieval fill values (RFVs), which indicate the absence of detectable levels of aerosol within the profile. In this study, using 4 years (20072008 and 2010-2011) of CALIOP version 3 L2 aerosol data, the occurrence frequency of daytime CALIOP profiles containing all RFVs (all-RFV profiles) is studied. In the CALIOP data products, the aerosol optical thickness (AOT) of any all-RFV profile is reported as being zero, which may introduce a bias in CALIOP-based AOT climatologies. For this study, we derive revised estimates of AOT for all-RFV profiles using collocated Moderate Resolution Imaging Spectroradiometer (MODIS) Dark Target (DT) and, where available, AErosol RObotic NEtwork (AERONET) data. Globally, all-RFV profiles comprise roughly $71 \%$ of all daytime CALIOP L2 aerosol profiles (i.e., including completely attenuated profiles), accounting for nearly half (45\%) of all daytime cloud-free L2 aerosol profiles. The mean collocated MODIS DT (AERONET) $550 \mathrm{~nm}$ AOT is found to be near 0.06 (0.08) for CALIOP all-RFV profiles. We further estimate a global mean aerosol extinction profile, a so-called "noise floor", for CALIOP all-RFV profiles. The global mean CALIOP AOT is then recomputed by replacing RFV values with the derived noise-floor values for both all-RFV and nonall-RFV profiles. This process yields an improvement in the agreement of CALIOP and MODIS over-ocean AOT.
\end{abstract}

\section{Introduction and motivation}

Cloud-Aerosol Lidar with Orthogonal Polarization (CALIOP) measurements provide critical information on aerosol vertical distribution for studies involving aerosol modeling (e.g., Campbell et al., 2010; Sekiyama et al., 2010; Yu et al., 2010; Zhang et al., 2011, 2014), air quality (e.g., Martin, 2008; Prados et al., 2010; Toth et al., 2014), aerosol climatic effects (e.g., Huang et al., 2007; Chand et al., 2009; Tesche et al., 2014; Thorsen and Fu, 2015; Alfaro-Contreras et al., 2016), and aerosol climatologies (Pappalardo et al., 2010; Wandinger et al., 2011; Amiridis et al., 2015; Toth et al., 2016). In addition, the column-integrated aerosol optical thickness (AOT) derived from level 2 (L2) CALIOP $532 \mathrm{~nm}$ observations is also widely used in comparing and combining with passive-based L2 aerosol retrievals for a comprehensive understanding of regional and global aerosol optical properties (e.g., Redemann et al., 2012). Two such passive-based systems are Aqua Moderate Resolution Imaging Spectroradiometer (MODIS), due to its proximity to CALIOP in the A-Train satellite constellation (Levy et al., 2013), and AErosol RObotic NEtwork (AERONET) sun photometers, which is the primary means for validation of satellite AOT retrievals (Holben et al., 1998).

It is well-documented that a discrepancy exists between CALIOP-derived AOTs and those from MODIS data (i.e., CALIOP retrievals lower than MODIS counterparts), albeit when invoking varying quality-assurance (QA)/quality control (QC) procedures across different time frames and spatial 
domains (e.g., Kacenelenbogen et al., 2011; Kittaka et al., 2011; Redemann et al., 2012; Kim et al., 2013; Ma et al., 2013). These studies tend to attribute the AOT differences to either uncertainties/cloud contamination in the MODIS retrieval or incorrect selection of the lidar ratio (extinctionto-backscatter ratio; Campbell et al., 2013) when deriving CALIOP aerosol extinction and subsequent AOT. In a similar fashion, CALIOP AOTs have been evaluated against AERONET-derived AOTs, with the disparities (CALIOP lower) attributed to incorrect CALIOP lidar ratio assumptions, cloud contamination, and differences in instrument viewing angles (Schuster et al., 2012; Omar et al., 2013).

While some studies cite the failure to detect tenuous aerosol layers as a possible factor in the aforementioned AOT discrepancy (Kacenelenbogen et al., 2011; Rogers et al., 2014), the extent to which these layer detection failures contribute to the AOT differences between multiple sensors has not been fully quantified. For L2 CALIOP profiles, an extinction coefficient retrieval is performed only for those range bins for which aerosol backscatter is detected above the algorithm noise floor. Otherwise, the bins are assigned fill values (retrieval fill values or RFVs) within the corresponding profile (i.e., -9999.00 s; Vaughan et al., 2009; Winker et al., 2013). In fact, all L2 CALIOP extinction profiles contain a nonzero percentage of RFVs. It is thus critical to recognize that since lidar-derived AOTs reflect the integration of rangeresolved extinction retrievals in the absence of multi-spectral instruments (i.e., Raman and high spectral resolution lidars, HSRLs), there will always be range bins in which aerosol is present below the detection thresholds of the instrument. Indeed, even in relatively "clean" conditions, low extinction but geometrically deep aerosol loadings can result in significant AOT contributions (Reid et al., 2017).

For a fairly large subset of CALIOP daytime measurements, no aerosol is detected anywhere within a column and hence no aerosol extinction is retrieved. This results in an aerosol extinction profile consisting entirely of RFVs (defined as CALIOP all-RFV profiles in this study). Assigning aerosol extinction coefficients to $0.0 \mathrm{~km}^{-1}$ to replace fill values during integration of the extinction coefficient profile results in a corresponding column AOT equal to zero. Note that this scenario further includes those profiles reduced to fill values in the process of applying QA procedures on a perbin basis (e.g., Campbell et al., 2012; Winker et al., 2013). Thus, it is plausible that a column exhibiting significant AOT may be underestimated in those cases in which the aerosol backscatter is both highly diffuse and unusually deep and thus consistently falls below the algorithm detection threshold.

The RFV issue is essentially a layer detectability problem which has been previously investigated in regional validation studies. For example, Rogers et al. (2014) evaluated the CALIOP layer and total-column AOT with the use of collocated HSRL data. Minimum detection thresholds for aerosol extinction were estimated as $0.012 \mathrm{~km}^{-1}$ at night and $0.067 \mathrm{~km}^{-1}$ during the daytime (in a layer median context). From a column-integrated perspective, CALIOP algorithms were found to underestimate AOT by about 0.02 during nighttime (attributed to tenuous aerosol layers in the free troposphere). During the daytime, due to the influence of the solar background signal, CALIOP algorithms were unable to detect about half of weak (AOT $<0.1)$ aerosol profiles.

At first glance, the RFV issue may seem superfluous and easily resolved in a subsequent study. In fact, the issue has already caused some confusion within the literature. For example, some studies (e.g., Redemann et al., 2012; Kim et al., 2013; Winker et al., 2013) include all-RFV profiles (i.e., $\mathrm{AOT}=0$ ) for analysis when evaluating climatological AOT characteristics. Campbell et al. $(2012,2013)$ and Toth et al. $(2013,2016)$, on the other hand, do not include all-RFV profiles while generating climatological averages. Clearly, the first approach introduces an artificial underestimation of mean AOT by including profiles in which AOT was not retrieved. The latter, however, presumably leads to an overestimation, since it is likely that all-RFV profiles reflect relatively low AOT cases (i.e., lower than any apparent mean sample value) in which CALIOP layer detection exhibits a lack of sensitivity to diffuse aerosol presence that caused nothing to be reported within the column. As a result, Kim et al. (2013) and Winker et al. (2013) report global mean CALIOP AOTs lower than those from Campbell et al. (2012), not including the profiles. Other factors (e.g., different temporal domains and QA metrics invoked) also contribute to the observed disparity in these global mean AOT computations. This state of affairs indicates a clear need to carefully quantify the occurrence frequency of all-RFV profiles on a global scale, and, if possible, derive representative column-integrated AOT values for RFV profiles.

Further, and as introduced above, for non-all-RFV profiles there remain range bins with RFVs in which low aerosol extinction is likely present (the sum of which, however, can result in a relatively significant AOT). Though some QA can filter obvious cases of attenuation-limited profiles (e.g., require aerosol presence within $250 \mathrm{~m}$ of the surface as in Campbell et al., 2012, 2013), the only current remedy otherwise is to accept RFV bins as equal to zero extinction, then integrating to obtain a column AOT estimate. It is compelling to investigate, in a manner similar to Rogers et al. (2014), what this quantitative effect is for climatological analysis.

In this paper, using 4 years (2007-2008 and 2010-2011) of daytime observations from CALIOP, Aqua MODIS, and AERONET, we investigate the RFV issue with an emphasis on the following questions:

1. What is the frequency of occurrence of all-RFV profiles in the daytime cloud-free CALIOP data set?

2. By collocating MODIS and AERONET AOTs with CALIOP cloud-free all-RFV profiles, what is the modal AOT associated with this phenomenon and how ran- 
domly are the data distributed as a function of passively derived AOT?

3. What is the quantitative underestimation in CALIOP AOT due to RFVs in profiles in which extinction is retrieved?

4. How much of the discrepancy between MODIS and CALIOP L2 over-ocean AOT retrievals can be explained by RFVs and all-RFV profiles?

We note that the primary CALIOP laser failed in March 2009, forcing the Cloud-Aerosol Lidar and Infrared Pathfinder Satellite Observations (CALIPSO) mission team to switch to a secondary laser. Therefore, 2 years of CALIOP aerosol data are analyzed prior to, and after, the switch to investigate any discernible difference in RFV statistics between the two lidar profiles.

\section{Data sets}

\subsection{CALIOP}

Orbiting aboard the CALIPSO satellite within the A-Train constellation (Stephens et al., 2002), CALIOP is a twowavelength (532 and $1064 \mathrm{~nm}$ ) polarization-sensitive (at $532 \mathrm{~nm}$ ) elastic backscatter lidar, observing the vertical distribution of aerosols and clouds in Earth's atmosphere since June 2006 (Winker et al., 2010). The $532 \mathrm{~nm}$ backscatter profiles measured by CALIOP are used to detect aerosol and cloud features and then retrieve corresponding particle extinction and subsequent AOTs (i.e., column-integrated extinction; Young and Vaughan, 2009) within layer boundaries determined by a multi-resolution layer detection scheme (Vaughan et al., 2009) and the assumption of a lidar ratio based upon aerosol or cloud type (Omar et al., 2005, 2009). For this study, $532 \mathrm{~nm}$ aerosol extinction coefficient data from the version 3 (V3) CALIPSO L2 $5 \mathrm{~km}$ Aerosol Profile (L2_05kmAProf) product are utilized (Winker et al., 2009; hereafter, all references to CALIOP data imply the $532 \mathrm{~nm}$ channel/product). These aerosol profiles are reported in $5 \mathrm{~km}$ segments and feature a vertical resolution of $60 \mathrm{~m}$ below an altitude of $20.2 \mathrm{~km}$ above mean sea level (a.m.s.l.). Only CALIOP data collected during daytime conditions are considered for this study, so that comparison with aerosol observations from MODIS and AERONET can be accomplished.

Prior to analysis, advanced QA procedures are performed on the L2_05kmAProf product. This QA scheme is similar to that employed in Campbell et al. (2012) and Winker et al. (2013) and involves several parameters included in the L2_05kmAProf product: Extinction_Coefficient_532 ( $\geq 0$ and $\left.\leq 1.25 \mathrm{~km}^{-1}\right)$, Extinction_QC_532 $(=0,1,2$, 16 , or 18), CAD_Score $(\geq-100$ and $\leq-20)$, and Extinction_Coefficient_Uncertainty_532 $\left(\leq 10 \mathrm{~km}^{-1}\right)$. The Integrated_Attenuated_Backscatter_532 $\left(\leq 0.01 \mathrm{sr}^{-1}\right)$ param- eter from the L2 $5 \mathrm{~km}$ aerosol layer (L2_05kmALay) product is also used as a QA metric. A detailed description of these QA checks is also outlined in our most recent CALIOP-based study (Toth et al., 2016). Extinction retrievals reported in the CALIOP data products that do not pass the full suite of QA tests are converted to RFVs. To limit the influence of clouds on our analysis (i.e., in order to ensure that the RFV issue is occurring due to layer detection sensitivity and not because of attenuation effects caused by cloud presence), each aerosol profile is cloud screened using the atmospheric volume description (AVD) parameter. We implement the strictest cloud screening possible, as profiles are flagged "cloudy" if any of the bins within the CALIOP column are classified as cloud.

\subsection{Aqua MODIS}

As an integral part of the payloads for NASA's Terra and Aqua satellites, MODIS is a 36-channel spectroradiometer with wavelengths ranging from 0.41 to $15 \mu \mathrm{m}$. Seven of these channels $(0.47-2.13 \mu \mathrm{m})$ are used to retrieve aerosol optical properties such as AOT (e.g., Levy et al., 2013). MODIS L2 aerosol products are reported at a spatial resolution of $10 \times 10 \mathrm{~km}^{2}$ at nadir, with a reported over-ocean expected error of $(-0.02-10 \%),(+0.04+10 \%)$ (Levy et al., 2013). However, uncertainties for individual retrievals may be larger (Shi et al., 2011). Also, thin cirrus contamination may exist in the MODIS aerosol products (e.g., Toth et al., 2013). In this study, the Effective_Optical_Depth_Best_Ocean $(550 \mathrm{~nm})$ parameter in the L2 Collection 6 (C6) Aqua MODIS aerosol product (MYD04_L2; Levy et al., 2013) is utilized. Only those retrievals flagged as "good" and "very good" are considered for analysis, as determined by the Quality_Assurance_Ocean parameter within the MYD04_L2 files.

\subsection{AERONET}

Developed for the purpose of furthering aerosol research and validating satellite retrievals, NASA's AERONET program is a federated worldwide system of ground-based sun photometers that collect measurements of aerosol optical and radiative properties (Holben et al., 1998). With a reported uncertainty of $\pm 0.01-0.02$ (although this estimate is low in the presence of unscreened cirrus clouds; e.g., Chew et al., 2011), AOTs are derived at several wavelengths ranging from 340 to $1640 \mathrm{~nm}$. Due to the lack of retrievals at the CALIOP wavelength, AOTs at $532 \mathrm{~nm}$ are computed from an interpolation of those derived at the 500 and $675 \mathrm{~nm}$ channels using an Ångström relationship (e.g., Shi et al., 2011; Toth et al., 2013). The highest-quality V2.0 AERONET data (level 2.0) are used in this study, as these are both cloud screened and quality assured (Smirnov et al., 2000). Also, only observations from coastal/island AERONET sites are considered for comparison with over-ocean CALIOP profiles, despite the potential overestimation of CALIOP AOT in coastal regions 
due to the CALIPSO aerosol-typing algorithms (e.g., Kanitz et al., 2014).

\section{Results and discussion}

\subsection{Demonstrating how CALIOP backscatter distribution can render profiles of all RFVs}

To demonstrate the nature of the RFV problem, Fig. 1 shows an example of cloud-free all-RFV CALIOP profiles embedded within curtain plots of total attenuated backscatter (TAB; Fig. 1a) and a matching vertical feature mask (VFM; Fig. 1b). Both plots were obtained from the CALIPSO Lidar Browse Images website (https://www-calipso.larc.nasa. gov/products/lidar/browse_images/production/), and the data were collected from CALIOP during the daytime on 2 July 2010 over the Arctic. The VFM shows that the range bins within the white box are classified as either surface or clear air features, and thus the corresponding L2 aerosol extinction coefficient profiles (not shown) are all-RFVs (i.e., the $\mathrm{AOT}=0$ scenario).

However, even under pristine conditions, aerosol particles are still present in the atmosphere. For example, the baseline maritime AOT is estimated to be $0.06 \pm 0.01$ (Kaufman et al., 2005; Smirnov et al., 2011). Thus, aerosol particles are likely present and yet undetected for the all-RFV cases shown in Fig. 1. Similar issues can also exist for profiles for which some aerosol is detected. This scenario is represented by the white arrow in the TAB and VFM plots, and the associated L2 aerosol extinction coefficient profile is depicted in Fig. 1c. An aerosol layer is evident from about 1.5 to $2.5 \mathrm{~km}$ a.m.s.l., leaving the remainder of the column as RFVs.

To further demonstrate the RFV phenomenon in the CALIOP data set, we next examine differences in TAB found in profiles for which all-RFVs were reported and those for which some extinction was retrieved. The CALIPSO Lidar level 1.5 data product (L1.5) is specifically leveraged for this task, as TAB for the all-RFVs class of data is not included in $\mathrm{L} 2$ data sets. The L1.5 product is a merging of the $\mathrm{L} 1$ and $\mathrm{L} 2$ products, cloud cleared, screened for nonaerosol features (e.g., surface, subsurface, totally attenuated, invalid), and available at $20 \mathrm{~km}$ (horizontal) and $60 \mathrm{~m}$ (vertical) resolutions (Vaughan et al., 2011). One month (February 2008) of daytime L1.5 TAB profiles over all global oceans were collocated with CALIOP AOTs derived from the L2_05kmAProf product. The data were limited to only those L1.5 averages that contain either four contiguous $5 \mathrm{~km} \mathrm{~L} 2$ all-RFV profiles or, conversely, four contiguous profiles for which extinction was retrieved in each. The selected TAB profiles were then averaged to a $20 \mathrm{~km}$ resolution for each altitude range (i.e., to obtain over global ocean mean TAB profiles).

The results of this analysis are shown in Fig. 2. Profiles of mean TAB over global oceans for February 2008 are shown in Fig. 2a; blue lines show all-RFV profiles and red lines show those for which some extinction was retrieved (i.e., non-all-RFVs). For most of the troposphere, little difference is observed between the two profiles (i.e., "clear sky" in the aggregate). However, the profiles begin to deviate below $3 \mathrm{~km}$ a.m.s.l., as larger TAB are found for the extinctionretrieved sample (peak TAB is $\sim 0.0031 \mathrm{~km}^{-1} \mathrm{sr}^{-1}$ ) compared to those profiles consisting of all-RFVs (peak TAB value is $\left.\sim 0.0017 \mathrm{~km}^{-1} \mathrm{sr}^{-1}\right)$. An additional analysis was conducted (not shown) using data over the Pacific Ocean to check for influences of geographic sampling (i.e., aerosol distribution) on the mean TAB profiles. Both the all-RFV and non-all-RFV mean TAB profiles increase at similar magnitudes after implementing this restriction, thus resulting in only a minor difference between the profiles.

Figure 2c shows a second pair of mean TAB profiles but now restricted to only those L2 CALIOP profiles collocated with MODIS AOTs between 0.03 and 0.07 (i.e., arbitrarily selected for low aerosol-loading scenarios). The collocation method applied here is the same as the one used by Toth et al. (2013), in which the midpoint of a $10 \times 10 \mathrm{~km}^{2}$ (at nadir) over-ocean MODIS AOT pixel is required to be within $8 \mathrm{~km}$ of the temporal midpoint of a $5 \mathrm{~km}$ L2 CALIOP aerosol profile. Observations outside this range are not considered. Whereas below, the modal MODIS AOT for passive retrievals collocated with all-RFV CALIOP profiles is about 0.05 , this restriction (i.e., 0.03-0.07 MODIS AOTs) is meant to investigate a more nuanced question. The presence of allRFV profiles is the result of several processes that can work either independently or in tandem. The dominant cause is, as described above, detection failure. RFVs also occur when the cloud-aerosol discrimination algorithm mistakenly classifies an aerosol layer as a cloud, and again when the extinction coefficients retrieved for a detected aerosol layer fail any of the QA metrics (e.g., an out-of-range extinction QC flag). This restriction is meant to limit the influence of layer misclassifications and occasional QA failures, and in particular, relatively high AOT cases in which unusually high TAB could influence the mean profile. Including such samples would degrade the accuracy of the TAB noise-floor estimate that we will use in subsequent analyses described in Sect. 3.5. Relatively speaking, though, the profiles in Fig. $2 \mathrm{c}$ are fairly similar to those of Fig. 2a. However, the relative deviation between the two samples now occurs below $2 \mathrm{~km}$ a.m.s.l., and the peak value of TAB for non-all-RFVs lowers to around $0.0025 \mathrm{~km}^{-1} \mathrm{sr}^{-1}$ (illustrating the effect of the MODIS AOT restriction). Also, for context, we include corresponding profiles of attenuated scattering ratio (TAB/molecular attenuated backscatter) for both analyses in Fig. $2 b$ and d.

The initial point of this comparison is that the mean TAB for all-RFV profiles is, as expected, lower than in those profiles for which extinction is retrieved above and within the planetary boundary layer. Thus, the figures represent a simple conceptual model of how profiles consisting of all-RFV cases arise with respect to diffuse aerosol backscatter structure and inherently lower signal-to-noise ratios (SNRs). While there 

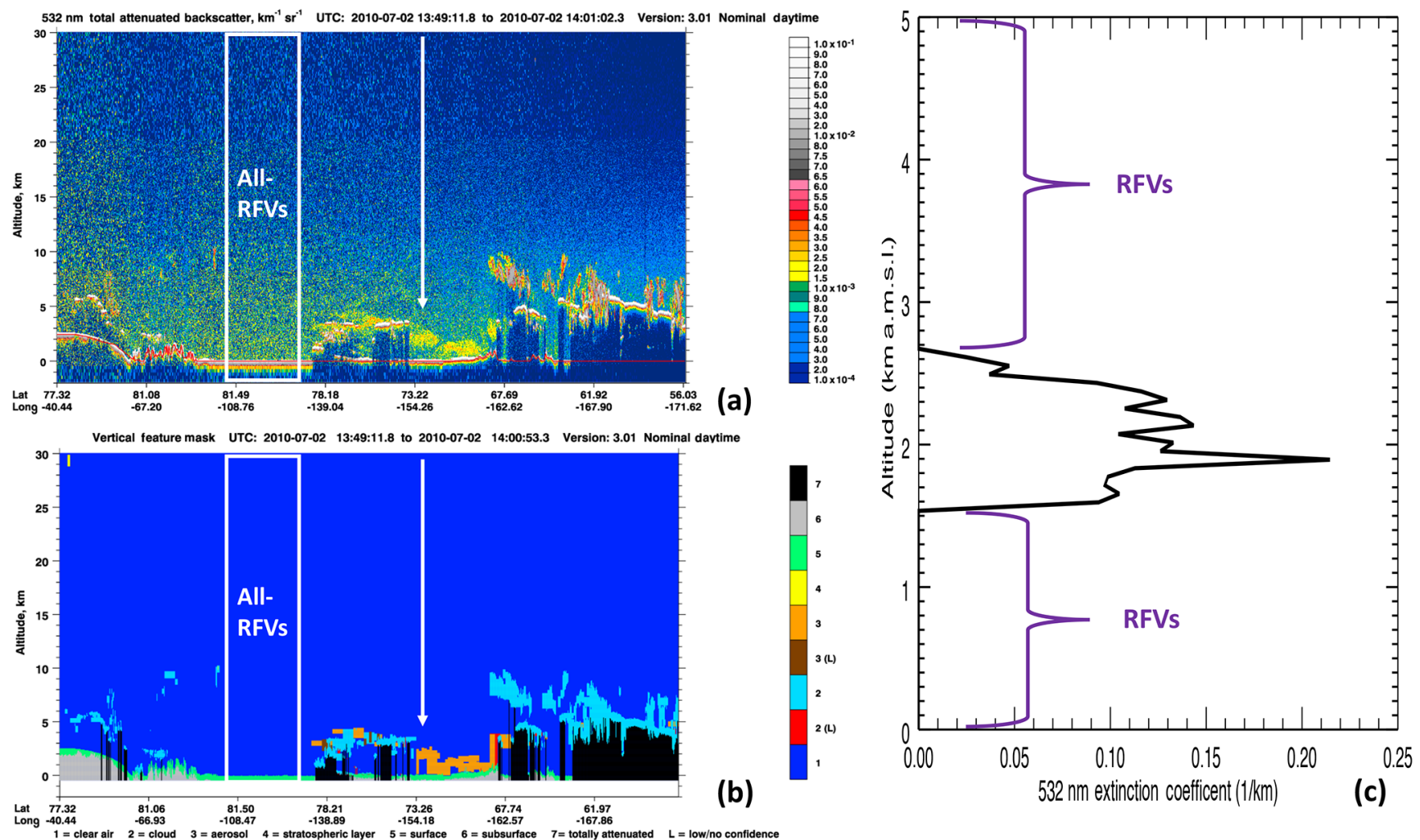

Figure 1. For data collected during the daytime on 2 July 2010 over the Arctic, browse image curtain plots of CALIPSO (a) 532 nm total attenuated backscatter $\left(\mathrm{km}^{-1} \mathrm{sr}^{-1}\right)$ and (b) corresponding vertical feature mask (VFM). The white box represents an example segment of the granule for which range bins in the associated level 2 (L2) aerosol extinction coefficient profile are all retrieval fill values (RFVs), as the VFM classified these bins as either surface (green) or clear-air (blue) features. The white arrow indicates a column in which some aerosol has been detected (orange), and the resultant L2 aerosol extinction profile for this column is shown in (c).

are several possible strategies for mitigating this issue for future global satellite lidar missions (discussed in the concluding remarks), the goal for this initial part of the study is to simply depict how the situation is manifested in the base backscatter product measured by the sensor.

\subsection{Frequency of occurrence for L2 CALIOP all-RFV aerosol profiles}

The next step of the analysis is to determine the frequency of occurrence of all-RFV profiles in the daytime CALIOP L2_05kmAProf archive. As these data will be collocated with both MODIS and AERONET data for subsequent analysis, no nighttime data are considered here. Table 1 summarizes the statistics of this analysis. For the 2010-2011 period, all-RFV profiles make up about $71 \%(66 \%)$ of all daytime CALIOP L2_05kmAProf profiles globally (global oceans-only). However, these statistics include those profiles for which the CALIOP signal was totally attenuated (e.g., by an opaque cloud layer), thus inhibiting aerosol detection near the surface. For context, the 2010-2011 occurrence frequencies of CALIOP that do not detect the surface are $39.9 \%$ (46.1\%) globally (global oceans-only). Roughly $30 \%$ of the full archive corresponds to cloud-free conditions (again, as described in Sect. 2.1, "cloud-free" refers to the implementation of the strictest CALIOP cloud screening possible, where no clouds are classified in the entire profile). Approximately $45 \%$ of all cloud-free profiles, and $25 \%$ of cloud-free overocean profiles, are also all-RFV profiles $(\sim 15$ and $8 \%$, respectively, in absolute terms). The over-ocean sample is considered below, given the relatively higher fidelity expected in the collocated MODIS AOT data (e.g., Levy et al., 2013).

We note that due to the primary CALIOP laser failing in 2009, Table 1 also includes results from a 2-year period (2007-2008) before the laser switch to examine any differences in the statistics of the RFV issue between the two lasers. The global frequency of occurrence of all-RFV profiles is consistent for both time periods (i.e., $70.4 \%$ for $2007-$ 2008 and $71.1 \%$ for $2010-2011$ ), and thus the remainder of this paper focuses on the 2010-2011 analysis alone. We find no evidence to suggest that laser performance exhibits any significant influence on the occurrence of per-range bin RFVs and all-RFV profiles within the L2 archive.

The spatial distribution of daytime over-ocean cloud-free all-RFV profiles is shown in Fig. 3. The percentage of cloud- 
Table 1. Statistical summary of the results for this study for the 2007-2008 and 2010-2011 periods, both globally and for global oceans only. The values in parentheses represent the percentages of each category relative to the entire CALIOP aerosol profile archive for each respective period.

\begin{tabular}{|c|c|c|c|c|}
\hline Number of $5 \mathrm{~km}$ CALIOP profiles & \multicolumn{2}{|c|}{ Globe } & \multicolumn{2}{|c|}{ Global oceans } \\
\hline Total & 41929328 & 41188208 & 27742947 & 27198000 \\
\hline All-RFV & $29503781(70.4 \%)$ & $29297919(71.1 \%)$ & $18190188(65.6 \%)$ & $18026930(66.3 \%)$ \\
\hline Cloud-free & $13317918(31.8 \%)$ & $13190530(32.0 \%)$ & $8006719(28.9 \%)$ & $7812682(28.7 \%)$ \\
\hline Cloud-free and all-RFV & $5764098(13.7 \%)$ & $5899221(14.3 \%)$ & $2089865(7.5 \%)$ & $2101155(7.7 \%)$ \\
\hline
\end{tabular}
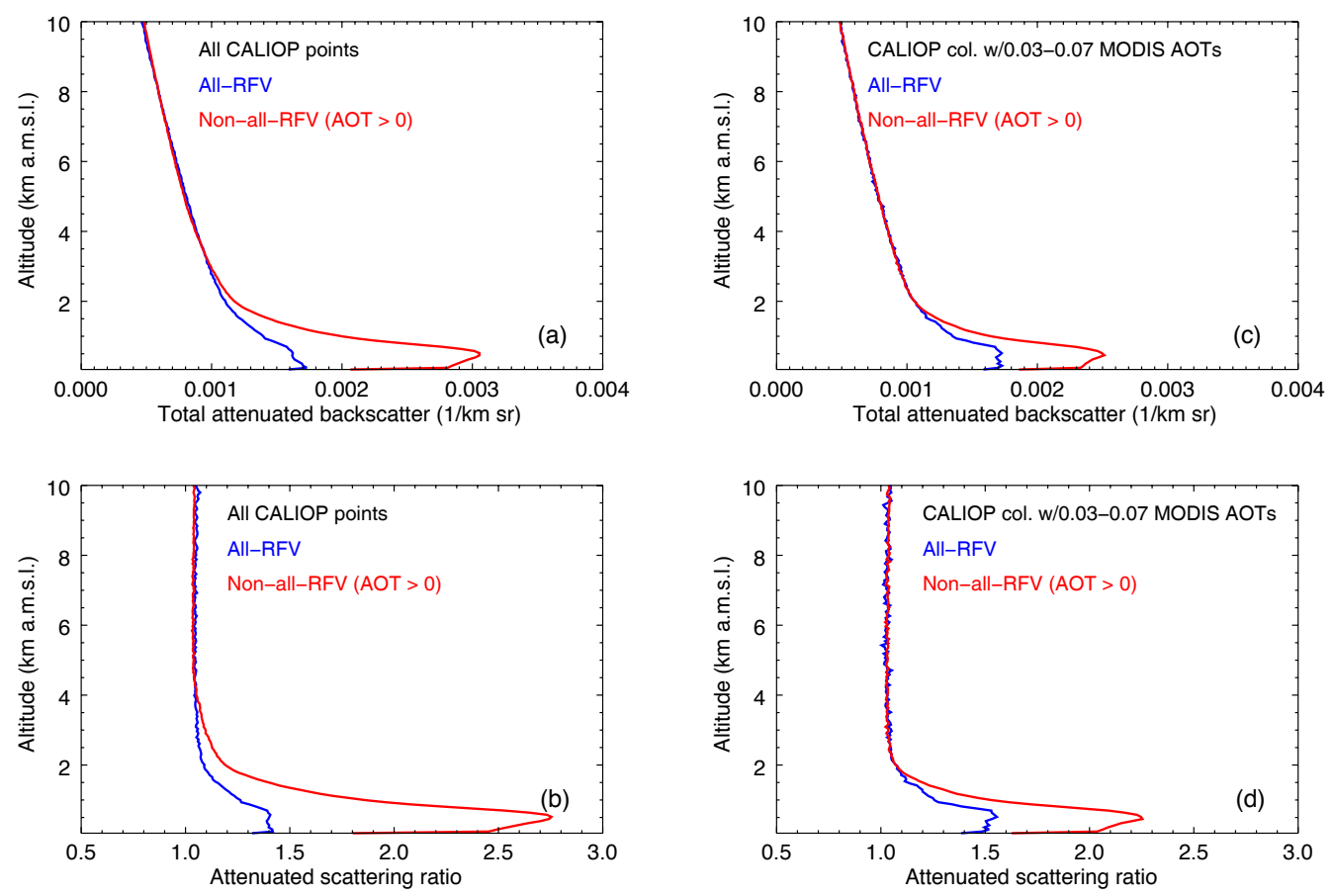

Figure 2. For February 2008, mean profiles of (a, c) level 1.5 total attenuated backscatter (TAB) and (b, d) attenuated scattering ratio (TAB/molecular attenuated backscatter) over global oceans, corresponding to level 2 all-RFV (in blue) and non-all-RFV (AOT $>0$; in red) profiles. The left column is from an analysis of all cloud-free CALIOP points over global oceans and the right column represents only those collocated with MODIS AOTs between 0.03 and 0.07 .

free CALIOP all-RFV aerosol profiles relative to all cloudfree CALIOP aerosol profiles is computed and presented on a $2^{\circ} \times 5^{\circ}$ latitude-longitude grid (Fig. 3a). Here we again restrict the analysis to cloud-free scenes to avoid ambiguities in RFV occurrence that are introduced by the presence of clouds. Regions with the largest occurrence frequencies of all-RFV profiles ( $>75 \%$ ) include the high latitudes of both the northern and southern hemispheres $(\mathrm{NH}$ and $\mathrm{SH}$, respectively). In fact, over snow surfaces, over $80 \%$ of CALIOP aerosol profiles are all-RFVs. Over permanent ice (e.g., Greenland), $\sim 99 \%$ are all-RFVs. In contrast, the tropics exhibit the lowest all-RFV profile occurrence frequencies $(<25 \%)$. The CALIOP archive contains a significant fraction of all-RFV profiles in polar regions, which is an impor- tant result with many ramifications for NASA Earth Observing System science. It is likely that all-RFVs correlate with both low aerosol-loading scenarios and high albedo surfaces (e.g., snow and sea ice).

Figure 3 also includes the spatial distribution of mean cloud-free CALIOP-derived AOT $\left(2^{\circ} \times 5^{\circ}\right.$ latitudelongitude resolution) without (Fig. 3b) and with (Fig. 3c) all-RFV profiles, demonstrating the quantitative impact of adding all-RFV AOT $=0$ profiles to the relative analysis. As mentioned above, both approaches have been implemented in past studies. Comparison of the plots reveals that including the all-RFV profiles in the average naturally lowers the mean AOT. To determine the areas for which mean AOTs are most impacted by all-RFVs, the ratio of mean AOT without 

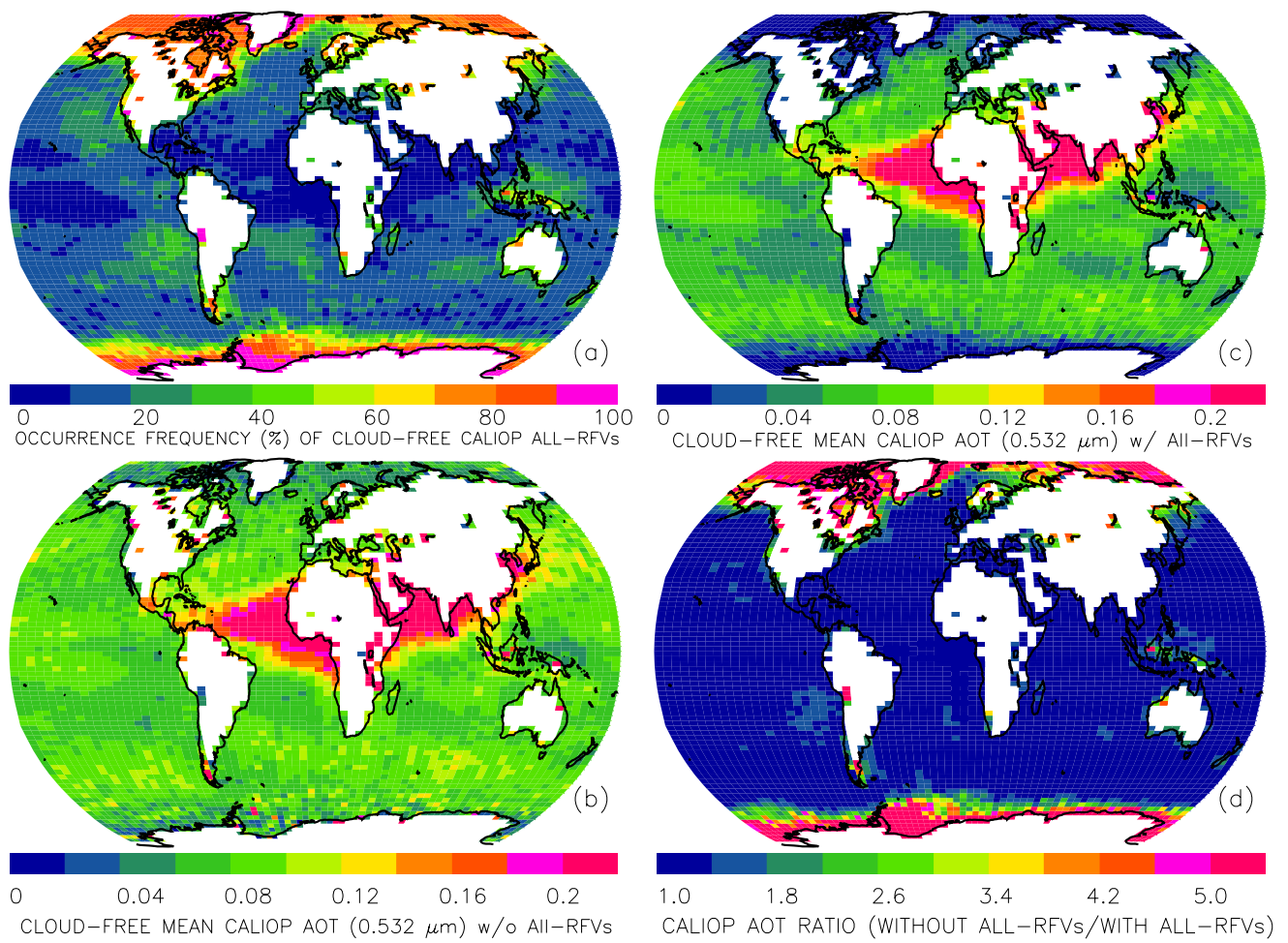

Figure 3. For 2010-2011, (a) the frequency of occurrence (\%) of cloud-free CALIOP profiles at $2^{\circ} \times 5^{\circ}$ latitude-longitude grid spacing. Also shown are the corresponding cloud-free mean CALIOP column AOTs (b) without and (c) with all-RFV profiles, and (d) the ratio of (b) to $(\mathbf{c})$.

and with all-RFV profiles (i.e., the ratio of Fig. $3 b$ to c) is shown in Fig. 3d. Little change in mean AOT is found for most of the oceans, with the exception of the high latitudes of each hemisphere. Overall, global ocean cloud-free mean AOT values of $\sim 0.09$ and $\sim 0.07$ are found, without and with all-RFV profiles, respectively. Such a decrease in mean AOT is expected, as $27 \%$ of CALIOP L2 over-ocean cloud-free aerosol profiles are all-RFVs. Also, regions with the largest all-RFV occurrence frequencies (i.e., high latitudes of both the $\mathrm{NH}$ and $\mathrm{SH}$ ) correspond to a greater lowering of mean AOT, compared with those regions (i.e., the tropics) where small all-RFV occurrence frequencies dominate.

\subsection{Collocation of MODIS AOT for over-ocean CALIOP all-RFV cases}

By collocating MODIS over-ocean AOT retrievals with CALIOP all-RFV profiles, we can estimate the distribution of AOT when algorithm detection/retrieval performance has been compromised. After collocation was performed (as described in Sect. 3.1), the number of all cloud-free CALIOP all-RFV profiles were binned by MODIS AOT in 0.01 increments (as depicted in Fig. 4), and separated into three latitude bands: the NH midlatitudes ( 30 to $60^{\circ} \mathrm{N}$; Fig. 4a), the tropics $\left(-30\right.$ to $30^{\circ} \mathrm{N}$; Fig. $\left.4 \mathrm{~b}\right)$, and the SH midlatitudes ( -60 to $-30^{\circ} \mathrm{N}$; Fig. 4c) where coincident data densities are reason- ably sufficient. For example, see Fig. 5a for numbers of valid MODIS over-ocean AOT data points available for collocation at $2^{\circ} \times 5^{\circ}$ latitude-longitude, based on "good" or "very good" over-ocean L2 MODIS AOT retrievals, relative to all corresponding retrievals. For context, Fig. 5b shows the associated spatial distribution of mean L2 MODIS AOT. We note that this includes only those MODIS points collocated with CALIOP, and thus the AOT distributions shown in Fig. 5b are likely different from distributions derived using the full MODIS data record (e.g., Levy et al., 2013). We also note, for the reference of the reader, that histograms of C6 MODIS AOT (not collocated with CALIOP) are provided in Levy et al. (2013).

Modal values of MODIS AOT for all-RFV profiles are found between 0.03 and 0.04 , with the exception of the 30 to $60^{\circ} \mathrm{N}$ band for which the greatest number of all-RFV profiles coincide with MODIS AOTs between 0.04 and 0.05. Thus, the primary mode of CALIOP RFV profiles is 0.03-0.05 from the perspective of MODIS. Corresponding mean and median MODIS AOTs for collocated CALIOP all-RFV profiles are presented in Table 2, with a mean value of 0.07 for the tropics and $\mathrm{NH}$ midlatitudes and 0.05 for the $\mathrm{SH}$ midlatitudes band (global mean of 0.06). Median AOTs are similar, though slightly lower, with a global median of 0.05 , reflecting the impact of the tail toward higher AOT in the sample 

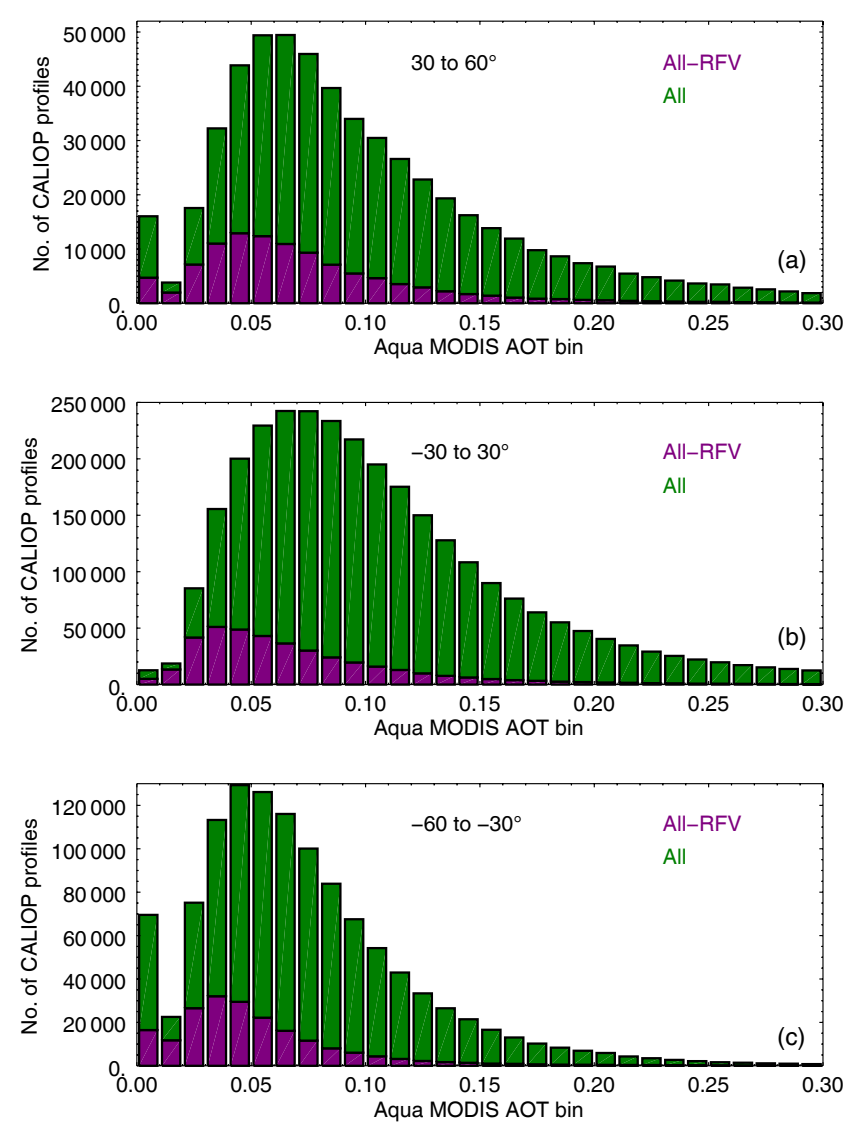

Figure 4. For 2010-2011, histograms of all over-ocean cloud-free CALIOP profiles (in green) and all-RFV profiles (in purple) as a function of collocated Aqua MODIS AOT (0.01 bins), for (a) 30 to $60^{\circ} \mathrm{N},(\mathbf{b})-30$ to $30^{\circ} \mathrm{N}$, and (c) -60 to $-30^{\circ} \mathrm{N}$.

distributions. We expect several modes of algorithm response contributing to these distributions, which are borne out in the CALIOP data: layer detection failures due to sensitivity limits, random noise in the attenuated backscatter measurement, and extinction retrieval failures.

While a similar distribution is exhibited for each region, the number of total observations for the tropics is much greater than that of the other two regions. Thus, the results of Fig. $4 \mathrm{~b}$ are more robust, which is primarily due to MODIS AOT data availability and collocation (Fig. 5a). Total MODIS occurrence frequencies are greatest in the tropics (generally $>50 \%$ ) and decrease poleward. The midlatitude regions exhibit occurrence frequencies less than $25 \%$, with near-zero frequencies observed in the high latitudes of the $\mathrm{NH}$ and $\mathrm{SH}$. We note that the low number of valid MODIS AOT retrievals in the high northern and southern latitudes, due at least partly to sea ice extent in these regions, presents a limitation for our study. That is, the areas for which all-RFV profiles occur most frequently (Fig. 3a) are the same areas with the fewest numbers of valid MODIS AOT retrievals. Note that in these regions, even for valid MODIS AOT re-
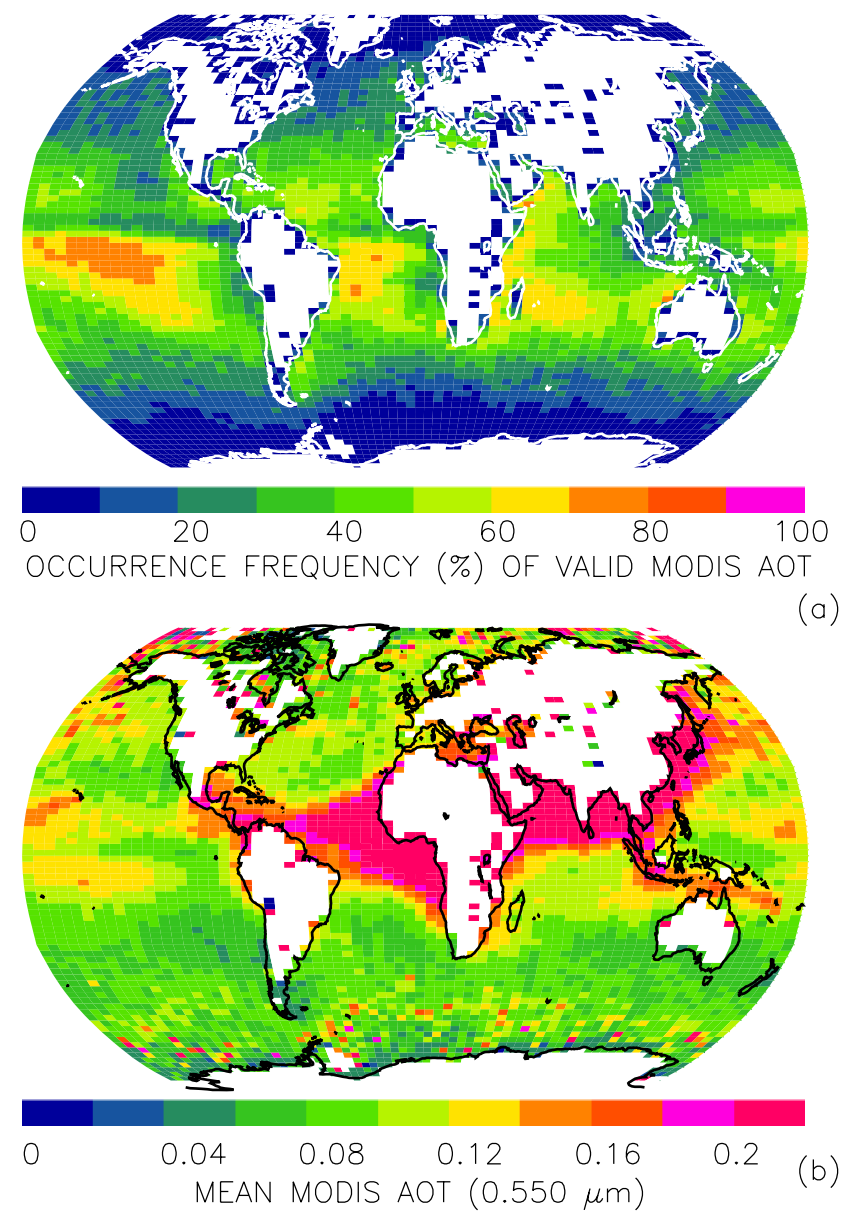

(a)

Figure 5. For 2010-2011, (a) frequency of occurrence (\%) of valid ("good" or "very good") over-ocean level 2 (L2) MODIS AOT retrievals, relative to all over-ocean L2 MODIS AOT retrievals, for every $2^{\circ} \times 5^{\circ}$ latitude-longitude grid box. Also shown is (b) the corresponding spatial distribution of mean L2 MODIS AOT for the same time period. This analysis includes only those MODIS points collocated with CALIOP.

trievals, biases due to subpixel sea ice contamination may still exist.

All-RFV profile occurrence frequencies are computed as a function of MODIS AOT in order to quantify the amount of CALIOP-derived AOT underestimation at a given MODISbased AOT. This underestimation (expressed as a percentage) was achieved by division of corresponding data counts in Fig. 4 and is shown in line plots in Fig. 6. The same regional sorting and MODIS AOT binning procedures from Fig. 4 are applied. A similar distribution is found for all three latitude bands, with the 0.01-0.02 MODIS AOT bin exhibiting the largest underestimation percentage, which gradually lowers toward higher MODIS AOT. CALIOP all-RFV underestimation near $50 \%$ is found for the $\mathrm{NH}$ and $\mathrm{SH}$ midlatitude regions (the red and black curves, respectively, of Fig. 6), respectively), for MODIS AOTs between 0.01 to 0.02 , and 
Table 2. Mean, median, and standard deviation of AOTs derived from Aqua MODIS (2010-2011) and AERONET (2007-2008; 2010-2011), both independently collocated with CALIOP all-RFV profiles.

\begin{tabular}{lrrr|rrr}
\hline Region & \multicolumn{3}{c|}{ MODIS } & \multicolumn{3}{c}{ AERONET } \\
\cline { 2 - 7 } & Mean & Median & $\begin{array}{r}\text { Standard } \\
\text { deviation }\end{array}$ & Mean & Median & $\begin{array}{r}\text { Standard } \\
\text { deviation }\end{array}$ \\
\hline 90 to $60^{\circ} \mathrm{S}$ & 0.05 & 0.04 & 0.10 & - & - & - \\
60 to $30^{\circ} \mathrm{S}$ & 0.05 & 0.04 & 0.11 & 0.04 & 0.04 & 0.01 \\
$30^{\circ} \mathrm{S}$ to $30^{\circ} \mathrm{N}$ & 0.07 & 0.06 & 0.11 & 0.10 & 0.10 & 0.19 \\
30 to $60^{\circ} \mathrm{N}$ & 0.07 & 0.06 & 0.13 & 0.09 & 0.08 & 0.07 \\
60 to $90^{\circ} \mathrm{N}$ & 0.07 & 0.06 & 0.17 & 0.05 & 0.04 & 0.04 \\
Globe & 0.06 & 0.05 & 0.12 & 0.08 & 0.07 & 0.11 \\
\hline
\end{tabular}

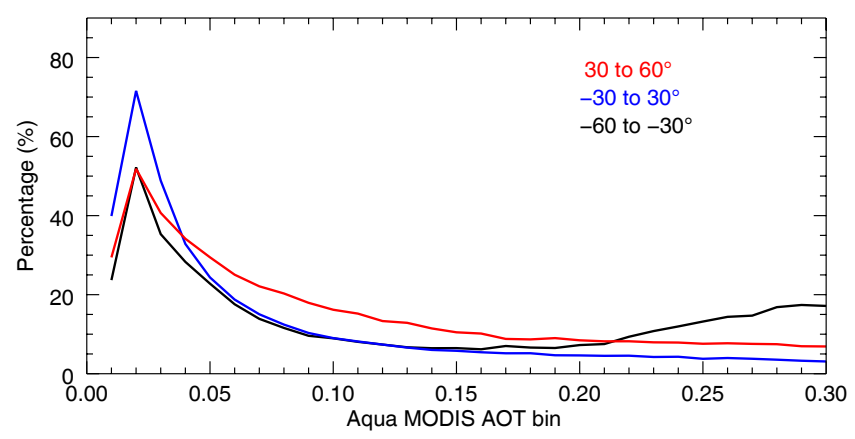

Figure 6. 2010-2011 frequency of occurrence (\%) of over-ocean cloud-free CALIOP all-RFV profiles, relative to all cloud-free CALIOP profiles, as a function of collocated Aqua MODIS AOT ( 0.01 bins), for 30 to $60^{\circ} \mathrm{N}$ (in red), -30 to $30^{\circ} \mathrm{N}$ (in blue), and -60 to $-30^{\circ} \mathrm{N}$ (in black).

this value increases to about $70 \%$ for the tropics (the blue curve of Fig. 6). This implies that $70 \%$ of all cloud-free CALIOP aerosol profiles in this MODIS AOT range are underestimated (i.e., CALIOP reports cloud-free all-RFV profiles $70 \%$ of the time for MODIS AOTs between 0.01 and $0.02)$.

While the distribution for the tropics is considered most robust, due to MODIS AOT availability in this region, it is important to note that increasingly lower AOTs (i.e., below $\sim 0.03$ ) are within the uncertainty range of MODIS AOT retrievals, and thus these results should be interpreted within the context of this caveat. Also, the relatively low underestimation percentages corresponding to MODIS AOTs less than 0.02 are believed to be an error, likely resulting from an artifact in the MODIS AOT retrievals/products.

\subsection{Collocation of CALIOP all-RFV profiles with AERONET}

AERONET data are considered the benchmark for satellite AOT retrievals (Holben et al., 1998). Thus, similarly to the over-ocean MODIS analysis above, CALIOP AOT and all-RFV profiles are examined using collocated AOTs

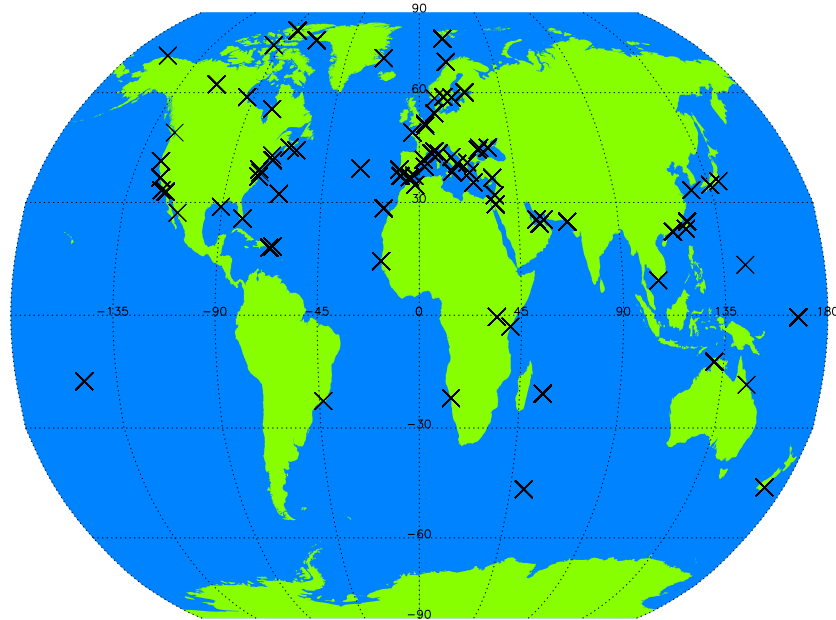

Figure 7. Map of the 93 coastal/island AERONET sites with level 2.0 data for the 2007-2008 and 2010-2011 periods, used for collocation with over-ocean CALIOP aerosol observations.

derived from measurements collected at coastal and island AERONET sites. Ninety-three sites are used, the locations of which are depicted globally in Fig. 7. Similarly to Sect. 3.3, CALIOP L2_05kmAProf data are spatially (within $0.4^{\circ}$ latitude-longitude) and temporally (within $30 \mathrm{~min}$ ) collocated with level 2.0 AERONET data. Note that we include all 4 years (2007-2008 and 2010-2011) for this analysis, as there are far fewer AERONET data points available in contrast to MODIS (e.g., Omar et al., 2013).

Figure 8 summarizes the results of the CALIOPAERONET collocation. In a similar manner to Fig. 4, Fig. 8a is a histogram of the number of cloud-free CALIOP aerosol profiles (all-RFV profiles and all available) for each 0.01 AERONET AOT bin. The overall distribution observed here is comparable to that from MODIS (Fig. 4), but noticeably noisier due to the limited AERONET data sample size. However, peak counts of all-RFV profiles occur for AERONET AOTs between 0.04 and 0.05 , which is roughly consistent with the MODIS comparisons. The corresponding mean AERONET AOTs of collocated CALIOP all-RFV profiles 

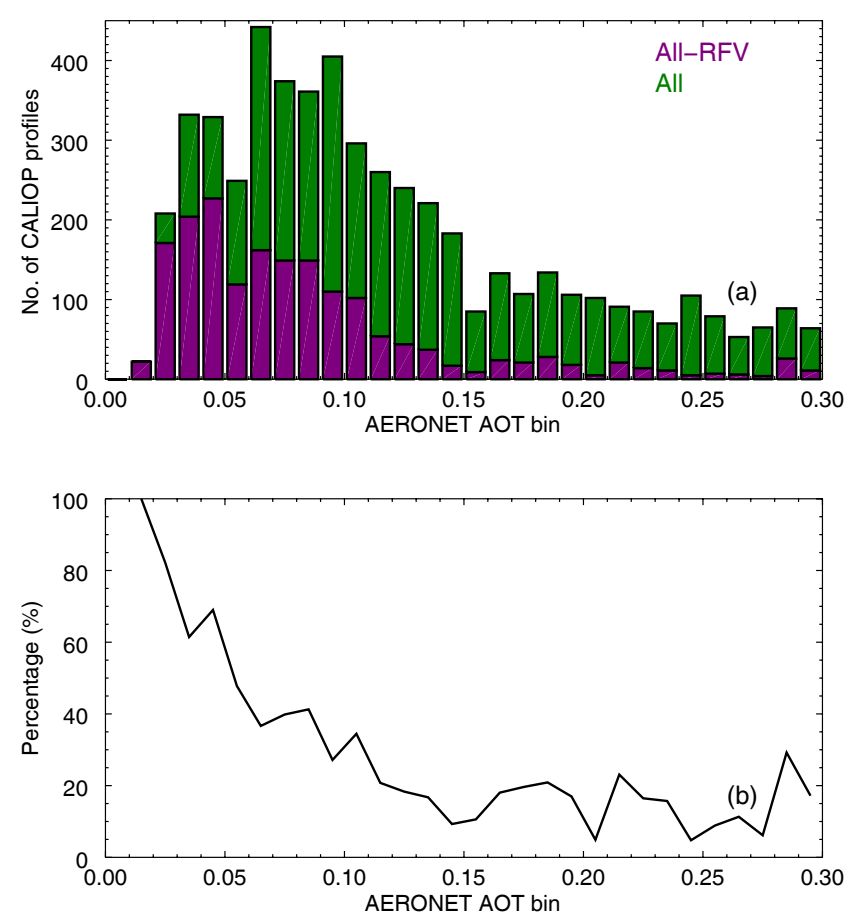

Figure 8. For the 2007-2008 and 2010-2011 periods: (a) histograms of all cloud-free CALIOP profiles (in green) and allRFV profiles (in purple), and (b) corresponding frequency of occurrence $(\%)$ of cloud-free CALIOP all-RFV profiles, relative to all cloud-free CALIOP profiles, both as a function of collocated coastal/island AERONET AOT (0.01 bins).

are generally higher than those found from MODIS, with values of 0.1 and 0.09 for the tropics and NH midlatitudes, respectively (Table 2), and a global mean (median) value of 0.08 (0.07). We note that this analysis may be influenced by residual cloud contamination of subvisible cirrus in the AERONET data set (e.g., Chew et al., 2011; Huang et al., 2012). We note that histograms of sun-photometer-derived AOT from Maritime Aerosol Network (MAN) observations (i.e., over-ocean component of AERONET; not collocated with CALIOP data) are shown in Smirnov et al. (2011).

Figure $8 \mathrm{~b}$ shows all-RFV profile occurrence frequencies as a function of AERONET AOT, computed by dividing the respective counts in Fig. 8a. Again, a noisier overall distribution is found compared with the line plots of Fig. 6. As expected, the 0.01-0.02 bin exhibits the largest underestimation percentage. However, while this value is $70 \%$ for the MODIS analysis (the blue curve of Fig. 6), it increases to $100 \%$ for AERONET, and we again conclude that an artifact is likely present in the MODIS retrievals for very low aerosol-loading cases. While the sample size is small, in the 4-year data set examined in this study, whenever AERONET measured an AOT lower than 0.02, the collocated CALIOP aerosol profiles contained only RFVs.

\subsection{Reconciling CALIOP AOT underestimation}

In this part of the study, we describe a proof-of-concept analysis that uses 1 month of data with the same spatiotemporal domain and conditions introduced in Sect. 3.1 to estimate the nominal underestimation of CALIOP AOT due to RFVs in otherwise high-fidelity L2 retrievals (i.e., those for which extinction is derived and the profile passes all QA/QC tests). This is achieved by retrieving extinction profiles from the mean global TAB profiles previously constructed from all-RFV profiles (i.e., as presented in Fig. 2). Characterizing these profiles, including those derived for all corresponding/collocated MODIS AOT (Fig. 2a, with an average MODIS AOT of 0.067) and MODIS AOT between 0.03 and 0.07 (Fig. 2c, with an average MODIS AOT of 0.045) to suppress the influence of random algorithm failure events at relatively high AOT, as TAB "noise floors", we then replace RFV bins with corresponding extinction and calculate column-integrated AOT. The premise here assumes that the distribution of aerosol depicted in the TAB noise floors is globally constant. This is highly uncertain, and we strongly caution that the purpose is to provide an initial demonstration of a practical way to correct RFVs in the CALIOP archive.

The aerosol extinction profiles for all-RFVs are derived in two steps. First, using an assumed lidar ratio of 29 sr (standard deviation of $10 \mathrm{sr}$; derived from constrained lidar ratios over ocean and represents background aerosols for the entire atmospheric column; Kim et al., 2017), an unconstrained extinction solution is generated from $20 \mathrm{~km}$ to the top of the surface-attached layer $(3.5 \mathrm{~km})$. In this step, the molecular and aerosol attenuation in the measured backscatter is accounted for at each range bin (from a top-down approach) by taking into account the overlying molecular and aerosol loading. The aerosol backscatter is then calculated by subtracting the unattenuated molecular backscatter from the newly derived aerosol-and-molecular-attenuation-corrected backscatter, from which the aerosol extinction is derived by multiplication of the lidar ratio. The top of the surface-attached layer is determined by inspection of the ratio between the measured backscatter and the modeled molecular attenuated backscatter, as provided in the CALIPSO L1.5 product. Integrating this extinction profile provides an estimate of the AOT overlying the surface-attached layer (AOT upper $_{\text {). The }}$ derived $\mathrm{AOT}_{\text {upper values are }} \sim 0.015$ and $\sim 0.01$ for the total all-RFV sample and AOT-limited sample, respectively. These values are not surprising, as they are in agreement with AERONET measurements obtained at the Mauna Loa site (elevation of $\sim 3.5 \mathrm{~km}$ a.m.s.l.; Alfaro-Contreras et al., 2016).

Next, a constrained extinction solution and optimized estimate of the lidar ratio are generated from $3.5 \mathrm{~km}$ to the surface using the AOT of this layer (i.e., column AOT $\left.\mathrm{AOT}_{\text {upper }}\right)$. This step is similar to the abovementioned approach, except now an iterative process is implemented to derive a lidar ratio for the layer. Resulting surface-attached 
layer lidar ratios are 43 and $30 \mathrm{sr}$ for the first and second case, respectively, with the latter value comparing reasonably well with the coastal marine lidar ratio of $\sim 28$ sr derived from AERONET analyses (Sayer et al., 2012). However, the lidar ratio solved for the all-RFV sample case is higher than that typical of marine aerosols (i.e., $~ 26$ sr; Dawson et al., 2015), which may be a result of uncertainties in both MODIS and CALIOP data sets. For example, the uncertainty of the lower end of MODIS AOT retrievals is on the order of -0.02-0.04 (Levy et al., 2013). These lidar ratios are also likely to have high biases due to biases in the daytime CALIOP V3 calibration scheme: the V3 daytime calibration coefficients are typically $10 \%$ to as much as $30 \%$ higher than their V4 counterparts, depending on location and season (Getzewich et al., 2016). Additionally, some all-RFV profiles may include nonmarine aerosols, which would further contribute to the high biases in the retrieved lidar ratios.

Despite these caveats, the resultant all-RFV extinction profiles are shown in Fig. 9, with values peaking near the surface and decreasing exponentially with height. These are thus considered the corresponding/approximated CALIOP extinction-based noise floors. Next, for those cloud-free, over-ocean, L2_05kmAProf CALIOP profiles from the same month (February 2008), RFV bins for profiles for which some measure of extinction has been observed and passed QA/QC were replaced with the corresponding extinction noise-floor values solved for the two TAB samples. Profiles were then reintegrated to yield RFV-corrected AOTs.

The results of this exercise are summarized in Table 3 . The first result, representing the inclusion of all-RFV profiles as is within bulk global samples (i.e., adding cases of AOT $=0$ to a given sample) shows a difference of 0.033 between collocated CALIOP and MODIS AOT. The noise-floor correction applied to both all-RFV profiles and those for which some extinction was solved yields AOT differences (i.e., MODISCALIOP) of -0.009 and 0.006 depending on the correction sample, which is an improvement ( $\sim 20 \%$ in absolute value) in the agreement of CALIOP and MODIS AOTs. If profiles with nominal extinction are not corrected and all-RFV profiles are ignored, a mean AOT difference of 0.025 is found with MODIS. Applying the noise-floor corrections for this scenario results in AOT differences of -0.013 and 0.001 or a $\sim 10-20 \%$ improvement (in absolute value) in the disparity in mean AOT between the two sensors. Lastly, we emphasize to the reader that this section describes only an initial attempt to resolve the RFV issue and can likely be improved in future studies. For example, the noise-floor extinction profile is derived using data from global oceans, while a regional dependency is possible. Also, longer spatial and temporal averages of CALIOP data would likely increase the SNRs and reduce the frequency of occurrence of the RFV issue.

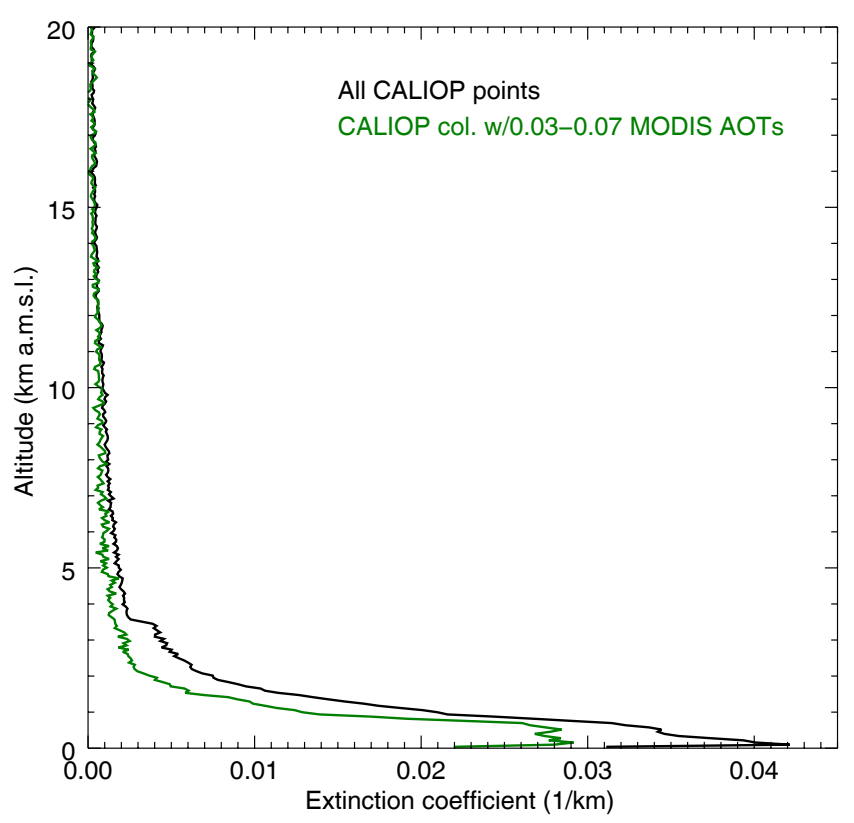

Figure 9. For February 2008 over cloud-free global oceans: the allRFV aerosol extinction coefficient profiles derived from the inversion algorithm. The black curve represents all cloud-free CALIOP profiles over global oceans, while the green curve is from an analysis restricted to only those CALIOP points collocated with MODIS AOTs between 0.03 and 0.07 .

\subsection{Case study: nighttime CALIOP all-RFV profile occurrence frequencies}

The analyses in this paper use daytime CALIOP data to allow for comparison with passively sensed aerosol observations from MODIS and AERONET. However, for context, in this section we conduct a case study for a 2-month (January and February 2008) period to investigate the occurrence frequencies of CALIOP all-RFV profiles during nighttime conditions. The same CALIOP products and QA procedures as described earlier are used here, and Table 4 summarizes the results of this analysis. During nighttime, about half of all global CALIOP aerosol profiles for this period are all-RFVs, but this statistic decreases to about $22 \%$ when restricted to cloud-free conditions. This percentage lowers even further for over-ocean profiles. Depending on the analysis, absolute decreases between daytime and nighttime all-RFV occurrence frequencies range from $\sim 8$ to $\sim 25 \%$. These findings are expected, as the lack of solar background signal during nighttime allows for an increased SNR and improves the ability of the CALIOP algorithms to detect aerosol layers.

\subsection{Anticipating version 4 CALIOP aerosol products}

Version 4 (V4) CALIOP L2 aerosol products were publicly released in November 2016. A case study was thus performed to assess changes in RFV impacts using these new products, again considering cloud-free over-global-ocean ob- 
Table 3. For February 2008 over cloud-free global oceans: the mean and standard deviation of collocated CALIOP and MODIS AOTs for various scenarios related to the treatment of non-all-RFV and all-RFV CALIOP aerosol profiles. For those scenarios that involve correction, [1] refers to analyses including all cloud-free CALIOP profiles over global oceans, while [2] refers to analyses restricted to CALIOP points collocated with MODIS AOTs between 0.03 and 0.07 . The corresponding aerosol extinction profiles used for RFV correction are shown in Fig. 9. Key results are highlighted with an asterisk.

\begin{tabular}{|c|c|c|c|c|c|c|c|c|c|}
\hline \multicolumn{5}{|c|}{ Scenario } & \multicolumn{2}{|c|}{ CALIOP AOT } & \multicolumn{2}{|c|}{ MODIS AOT } & \multirow{2}{*}{$\begin{array}{c}\Delta \mathrm{AOT} \\
(\mathrm{MODIS}-\mathrm{CALIOP})\end{array}$} \\
\hline $\begin{array}{c}\text { Corrected } \\
\text { non-all-RFVs? }\end{array}$ & $\begin{array}{l}\text { All-RFVs } \\
\text { set to zero? }\end{array}$ & $\begin{array}{c}\text { All-RFVs } \\
\text { ignored? }\end{array}$ & $\begin{array}{l}\text { All-RFVs } \\
\text { corrected? }\end{array}$ & $\begin{array}{l}\text { Correction } \\
\text { subset }\end{array}$ & Mean & $\begin{array}{l}\text { Standard } \\
\text { deviation }\end{array}$ & Mean & $\begin{array}{r}\text { Standard } \\
\text { deviation }\end{array}$ & \\
\hline & $\checkmark$ & & & & 0.084 & 0.113 & 0.117 & 0.133 & 0.033 \\
\hline$\checkmark$ & & & $\checkmark$ & [1] & 0.126 & 0.107 & 0.117 & 0.133 & $-0.009 *$ \\
\hline$\checkmark$ & & & $\checkmark$ & [2] & 0.111 & 0.109 & 0.117 & 0.133 & $0.006^{*}$ \\
\hline & & $\checkmark$ & & & 0.098 & 0.116 & 0.123 & 0.123 & 0.025 \\
\hline$\checkmark$ & & $\checkmark$ & & [1] & 0.136 & 0.112 & 0.123 & 0.123 & -0.013 \\
\hline$\checkmark$ & & $\checkmark$ & & [2] & 0.122 & 0.114 & 0.123 & 0.123 & 0.001 \\
\hline
\end{tabular}

Table 4. All-RFV CALIOP occurrence frequencies for 2 months (January and February 2008) from various analyses using daytime and nighttime data, as well as their corresponding absolute differences.

\begin{tabular}{|c|c|c|c|}
\hline \multicolumn{2}{|c|}{ Analysis } & \multirow{2}{*}{$\begin{array}{r}\text { All points } \\
70.7 \%\end{array}$} & \multirow{2}{*}{$\begin{array}{r}\text { Cloud-free } \\
46.7 \%\end{array}$} \\
\hline Daytime & Globe & & \\
\hline & Global oceans & $63.4 \%$ & $21.8 \%$ \\
\hline \multirow{2}{*}{ Nighttime } & Globe & $53.5 \%$ & $22.0 \%$ \\
\hline & Global oceans & $52.2 \%$ & $14.0 \%$ \\
\hline \multirow[t]{2}{*}{ Nighttime - daytime } & Globe & $-17.2 \%$ & $-24.7 \%$ \\
\hline & Global oceans & $-11.2 \%$ & $-7.8 \%$ \\
\hline
\end{tabular}

servations during daytime conditions. Whereas the broader point of the paper is a conceptualization of the lowerthreshold sensitivity of CALIOP to aerosol presence and the global distribution and impact on overall archive availability, this analysis is included for general consistency. Specifically, V4 data feature improved calibrations of level 1 (L1) backscatter, as well as improved cloud-aerosol discrimination and surface detection that may increase the detection sensitivity of diffuse aerosol layers that are reflected in L2 aerosol extinction retrievals. This may then result in a possible decrease in the occurrence of all-RFV profiles overall.

A 2-month V4 (January and February 2008) analysis using QA aerosol profile data (L2_05kmAPro-Standard-V410) reveals a $4 \%$ relative decrease ( $1 \%$ absolute decrease) in global all-RFV profile occurrence frequencies between V3 and V4. Without QA screening (Sect. 2.1), a $15 \%$ relative decrease ( $2 \%$ absolute decrease) is found in the occurrence frequency of all-RFV profiles between versions. A supplemental analysis was also conducted through the use of the CALIOP aerosol layer product (L2_05kmALay-StandardV4-10) with alternative cloud screening (i.e., cloud optical depth $=0$ instead of the AVD parameter), the results of which are consistent with those from the L2_05kmAPro-Standard-
V4-10 test. Though this is an initial look at this important new data set, it appears that improvements in instrument calibration have some positive influence on retrieval sensitivity, though the broader impact of all-RFV profiles as a limiting factor on the breadth of the CALIOP archive, particularly at the poles, mostly remains.

\section{Conclusions}

Since June 2006, the NASA Cloud-Aerosol Lidar with Orthogonal Polarization (CALIOP) instrument has provided a unique global space-borne view of aerosol vertical distribution in Earth's atmosphere. As indicated by this study, a significant portion of level 2 (L2) CALIOP $532 \mathrm{~nm}$ aerosol profiles consist of retrieval fill values (RFVs) throughout the entire range-resolved column (i.e., all-RFVs), overwhelmingly the result of instrument sensitivity and algorithm layer detection limits. The relevant impact of the all-RFV profile is a subsequent column-integrated aerosol optical thickness (AOT) equal to zero.

Using 4 years (2007-2008 and 2010-2011) of daytime CALIOP version $3 \mathrm{~L} 2$ aerosol products, the frequency of occurrence of all-RFV profiles within the CALIOP archive is quantified. L2 retrieval underestimation and lower detectability limits of CALIOP-derived AOT are assessed using collocated L2 aerosol retrievals from over-ocean Aqua Moderate Resolution Imaging Spectroradiometer (MODIS) and coastal/island AErosol RObotic NEtwork (AERONET) measurements. The results are partitioned into three latitude bands: Northern Hemisphere midlatitudes $\left(30\right.$ to $\left.60^{\circ} \mathrm{N}\right)$, tropics $\left(-30\right.$ to $\left.30^{\circ} \mathrm{N}\right)$, and Southern Hemisphere midlatitudes $\left(-60\right.$ to $\left.-30^{\circ} \mathrm{N}\right)$. The primary findings of this study are as follows:

1. Analysis of CALIOP level 1.5 attenuated backscatter data reveals that all-RFV profiles are primarily the result of diffuse aerosol layers with inherently lower signal-to- 
noise ratios (SNRs) that are below CALIOP layer detection limits.

2. All-RFV profiles make up $71 \%(66 \%)$ of all daytime CALIOP L2 aerosol profiles globally (global oceansonly), although this includes completely attenuated columns. For cloud-free CALIOP L2 aerosol profiles, $45 \%(27 \%)$ globally (global oceans-only) are all-RFV profiles. The largest relative all-RFV profile occurrence frequencies $(>75 \%)$ are found in the high latitudes of both hemispheres and are smallest $(<25 \%)$ in the tropics. The results of this study indicate that there is a significant daytime observational gap in CALIOP aerosol products near the poles, which is a critically important finding for community awareness.

3. The primary mode of CALIOP all-RFV profiles corresponds to MODIS AOTs of $0.03-0.05$, which is largely consistent with an AERONET-based analysis. Also, we found that a small fraction of AERONET data have AOTs lower than 0.02, of which all collocated CALIOP L2 profiles are all-RFVs. This finding is consistent with the lowest detectable CALIOP aerosol optical depth range of $0.02-0.04$, as hypothesized by Kacenelenbogen et al. (2011). Note that this conclusion hints that CALIOP may not detect very thin aerosol layers (i.e., AOTs $<0.05$ ), which account for $\sim 10-20 \%$ of the AOT spectrum and are of climatological importance (e.g., Smirnov et al., 2011; Levy et al., 2013). Also, these CALIOP-undetected thin aerosol layers are important for various applications, ranging from data assimilation to aerosol indirect effects.

4. As a preliminary study, aerosol extinction coefficient values for two distinct CALIOP all-RFV profile samples are derived using an inversion algorithm applied to corresponding attenuated backscatter data, and a collection of RFV-corrected mean CALIOP AOTs are estimated for a 1-month case study. The mean over-ocean CALIOP AOTs increase 10-20\% (in absolute value) after correction, with a closer match to collocated Aqua MODIS mean over-ocean AOT.

5. A small decrease in all-RFV profile occurrence is found from version 4 CALIOP data, which are undergoing widespread release at the time of writing. Still, the larger-scale impact of all-RFV profiles remains.

This research demonstrates that all-RFV profiles exert a significant influence on the L2 CALIOP AOT archive, as these data compose nearly half of global cloud-free CALIOP aerosol points. Disagreements exist in the literature on how to handle all-RFV profiles when generating level 3 AOT statistics. Some studies have set the integrated AOTs of allRFV profiles to zero, for instance, and included them. However, analyses with passive-based sensors presented in this study reveal these AOTs are most certainly nonzero (global mean values of 0.06 for MODIS and 0.08 for AERONET). These findings are not surprising, as this is the baseline AOT range expected under clean maritime conditions (Kaufman et al., 2001, 2005).

This research also shows that CALIOP RFVs caused by lower backscatter threshold sensitivities to highly diffuse aerosols contribute significantly to the discrepancy between CALIOP AOT and those derived from passive sensors like MODIS. Previous studies have mostly attributed this offset to the selection of the CALIOP lidar ratio (extinctionto-backscatter ratio) or errors in passive aerosol retrievals. Multi-spectral lidar measurements can begin to close the gap, but will experience SNR issues of their own.

By characterizing lower detection limits of CALIOPderived extinction and AOT, the potential exists for innovations in instrumentation design and algorithm development of future lidar missions, such as those affiliated with the NASA Aerosol-Cloud-Ecosystem (ACE) mission or the signal processing effort of Marais et al. (2016). Specifically, increasing the intensity of the lidar signal or implementing larger spatial averaging schemes may help to lower the occurrence frequency of all-RFV profiles and relative RFV occurrence per range bin in L2 products. Questions, however, arise in terms of developing data sets with sufficient spatial and temporal resolution versus requirements for optimal data densities, and which is more significant for a given project. Regardless of the potential solution, science teams of current and future lidar systems should carefully consider the existence of RFVs in project data sets.

Data availability. CALIPSO data were obtained from the NASA Langley Research Center Atmospheric Science Data Center (https: //eos.web.larc.nasa.gov/; Winker et al., 2009; last access: 1 December 2017). MODIS data were obtained from NASA Goddard Space Flight Center (https://ladsweb.nascom.nasa.gov/; Levy et al., 2013; last access: 22 January 2018). AERONET data were obtained from the project website (https://aeronet.gsfc.nasa.gov/; Holben et al., 1998; last access: 22 January 2018).

Competing interests. The authors declare that they have no conflict of interest.

Acknowledgements. This research was funded with the support of the Office of Naval Research through contract N00014-16-12040 (grant 11843919) and the NASA Earth and Space Science Fellowship program. Authors Jianglong Zhang and Travis D. Toth acknowledge the support from NASA grants NNX14AJ13G and NNX17AG52G. Author James R. Campbell acknowledges the support of the NASA Interagency Agreement IAARPO201422 on behalf of the CALIPSO Science Team. We acknowledge the AERONET program and the contributing principal investigators and their staff for coordinating the sites and data used for this investigation. 
Edited by: Vassilis Amiridis

Reviewed by: John Yorks and two anonymous referees

\section{References}

Alfaro-Contreras, R., Zhang, J., Campbell, J. R., and Reid, J. S.: Investigating the frequency and interannual variability in global above-cloud aerosol characteristics with CALIOP and OMI, Atmos. Chem. Phys., 16, 47-69, https://doi.org/10.5194/acp-16-472016, 2016.

Amiridis, V., Marinou, E., Tsekeri, A., Wandinger, U., Schwarz, A., Giannakaki, E., Mamouri, R., Kokkalis, P., Binietoglou, I., Solomos, S., Herekakis, T., Kazadzis, S., Gerasopoulos, E., Proestakis, E., Kottas, M., Balis, D., Papayannis, A., Kontoes, C., Kourtidis, K., Papagiannopoulos, N., Mona, L., Pappalardo, G., Le Rille, O., and Ansmann, A.: LIVAS: a 3-D multi-wavelength aerosol/cloud database based on CALIPSO and EARLINET, Atmos. Chem. Phys., 15, 7127-7153, https://doi.org/10.5194/acp15-7127-2015, 2015.

Campbell, J. R., Reid, J. S., Westphal, D. L., Zhang, J., Hyer, E. J., and Welton, E. J.: CALIOP aerosol subset processing for global aerosol transport model data assimilation, IEEE J. Sel. Top. Appl., 3, 203-214, 2010.

Campbell, J. R., Tackett, J. L., Reid, J. S., Zhang, J., Curtis, C. A., Hyer, E. J., Sessions, W. R., Westphal, D. L., Prospero, J. M., Welton, E. J., Omar, A. H., Vaughan, M. A., and Winker, D. M.: Evaluating nighttime CALIOP $0.532 \mu \mathrm{m}$ aerosol optical depth and extinction coefficient retrievals, Atmos. Meas. Tech., 5, 2143-2160, https://doi.org/10.5194/amt-5-2143-2012, 2012.

Campbell, J. R., Reid, J. S., Westphal, D. L., Zhang, J., Tackett, J. L., Chew, B. N., Welton, E. J., Shimizu, A., Sugimoto, N., and Aoki, K.: Characterizing the vertical profile of aerosol particle extinction and linear depolarization over Southeast Asia and the Maritime Continent: the 2007-2009 view from CALIOP, Atmos. Res., 122, 520-543, https://doi.org/10.1016/j.atmosres.2012.05.007, 2013.

Chand, D., Wood, R., Anderson, T. L., Satheesh, S. K., and Charlson, R. J.: Satellite-derived direct radiative effect of aerosols dependent on cloud cover, Nat. Geosci., 2, 181-184, 2009.

Chew, B. N., Campbell, J. R., Reid, J. S., Giles, D. M., Welton, E. J., Salinas, S. V., and Liew, S. C.: Tropical cirrus cloud contamination in sun photometer data, Atmos. Environ., 45, 6724-6731, 2011.

Dawson, K. W., Meskhidze, N., Josset, D., and Gassó, S.: Spaceborne observations of the lidar ratio of marine aerosols, Atmos. Chem. Phys., 15, 3241-3255, https://doi.org/10.5194/acp15-3241-2015, 2015.

Getzewich, B. J., Tackett, J. L, Kar, J., Garnier, A., Vaughan, M. A., and Hunt, B.: CALIOP Calibration: Version 4.0 Algorithm Updates, The 27th International Laser Radar Conference (ILRC 27), EPJ Web of Conferences, 119, 04013, https://doi.org/10.1051/epjconf/201611904013, 2016.

Holben, B. N., Eck, T. F., Slutsker, I., Tanré, D., Buis, J. P., Setzer, A., Vermote, E., Reagan, J. A., Kaufman, Y., Nakajima, T., Lavenu, F., Jankowiak, I., and Smirnov, A.: AERONET - A Federated Instrument Network and Data Archive for Aerosol Characterization, Remote Sens. Environ., 66, 1-16, 1998.
Huang, J., Minnis, P., Yi, Y., Tang, Q., Wang, X., Hu, Y., Liu, Z., Ayers, K., Trepte, C., and Winker, D.: Summer dust aerosols detected from CALIPSO over the Tibetan Plateau, Geophys. Res. Lett., 34, L18805, https://doi.org/10.1029/2007GL029938, 2007.

Huang, J., Hsu, N. C., Tsay, S., Holben, B. N., Welton, E. J., Smirnov, A., Jeong, M.-J., Hansell, R. A., Berkoff, T. A., Liu, Z., Liu, G.-R., Campbell, J. R., Liew, S. C., and Barnes, J. E.: Evaluations of cirrus contamination and screening in ground aerosol observations using collocated lidar systems, J. Geophys. Res., 117, D15204, https://doi.org/10.1029/2012JD017757, 2012.

Kacenelenbogen, M., Vaughan, M. A., Redemann, J., Hoff, R. M., Rogers, R. R., Ferrare, R. A., Russell, P. B., Hostetler, C. A., Hair, J. W., and Holben, B. N.: An accuracy assessment of the CALIOP/CALIPSO version 2/version 3 daytime aerosol extinction product based on a detailed multi-sensor, multi-platform case study, Atmos. Chem. Phys., 11, 3981-4000, https://doi.org/10.5194/acp-11-3981-2011, 2011.

Kanitz, T., Ansmann, A., Foth, A., Seifert, P., Wandinger, U., Engelmann, R., Baars, H., Althausen, D., Casiccia, C., and Zamorano, F.: Surface matters: limitations of CALIPSO V3 aerosol typing in coastal regions, Atmos. Meas. Tech., 7, 2061-2072, https://doi.org/10.5194/amt-7-2061-2014, 2014.

Kaufman, Y. J., Smirnov, A., Holben, B. N., and Dubovik, O.: Baseline maritime aerosol: methodology to derive the optical thickness and scattering properties, Geophys. Res. Lett., 28, 32513254, 2001.

Kaufman, Y. J., Boucher, O., Tanré, D., Chin, M., Remer, L. A., and Takemura, T.: Aerosol anthropogenic component estimated from satellite data, Geophys. Res. Lett., 32, L17804, https://doi.org/10.1029/2005GL023125, 2005.

Kim, M. H., Kim, S. W., Yoon, S. C., and Omar, A. H.: Comparison of aerosol optical depth between CALIOP and MODIS-Aqua for CALIOP aerosol subtypes over the ocean, J. Geophys. Res.Atmos., 118, 13241-13252, 2013.

Kim, M. H., Omar, A. H., Vaughan, M. A., Winker, D. M., Trepte, C. R., Hu, Y., Z. Liu, Z., and Kim, S.-W.: Quantifying the low bias of CALIPSO's column aerosol optical depth due to undetected aerosol layers, J. Geophys. Res.-Atmos., 122, 1098 1113, https://doi.org/10.1002/2016JD025797, 2017.

Kittaka, C., Winker, D. M., Vaughan, M. A., Omar, A., and Remer, L. A.: Intercomparison of column aerosol optical depths from CALIPSO and MODIS-Aqua, Atmos. Meas. Tech., 4, 131-141, https://doi.org/10.5194/amt-4-131-2011, 2011.

Levy, R. C., Mattoo, S., Munchak, L. A., Remer, L. A., Sayer, A. M., Patadia, F., and Hsu, N. C.: The Collection 6 MODIS aerosol products over land and ocean, Atmos. Meas. Tech., 6, 29893034, https://doi.org/10.5194/amt-6-2989-2013, 2013.

Ma, X., Bartlett, K., Harmon, K., and Yu, F.: Comparison of AOD between CALIPSO and MODIS: significant differences over major dust and biomass burning regions, Atmos. Meas. Tech., 6, 2391-2401, https://doi.org/10.5194/amt-6-2391-2013, 2013.

Marais, W., Holz, R. E., Hui, Y. H., Kuehn, R. E., Eloranta, E. E., and Willett, R. M.: Approach to simultaneously denoise and invert backscatter and extinction from photon-limited atmospheric lidar observations, Appl. Optics, 55, 8316-8334, https://doi.org/10.1364/AO.55.008316, 2016.

Martin, R. V.: Satellite remote sensing of surface air quality, Atmos. Environ., 42, 7823-7843, 2008. 
Omar, A. H., Won, J. G., Winker, D. M., Yoon, S. C., Dubovik, O., and McCormick, M. P.: Development of global aerosol models using cluster analysis of Aerosol Robotic Network (AERONET) measurements, J. Geophys. Res.-Atmos., 110, D10S14, https://doi.org/10.1029/2004JD004874, 2005.

Omar, A., Winker, D., Kittaka, C., Vaughan, M., Liu, Z., Hu, Y., Trepte, C., Rogers, R., Ferrare, R., Kuehn, R., and Hostetler, C.: The CALIPSO Automated Aerosol Classification and Lidar Ratio Selection Algorithm, J. Atmos. Ocean. Tech., 26, 1994-2014, https://doi.org/10.1175/2009JTECHA1231.1, 2009.

Omar, A. H., Winker, D. M., Tackett, J. L., Giles, D. M., Kar, J., Liu, Z., Vaughan, M. A., Powell, K. A., and Trepte, C. R.: CALIOP and AERONET aerosol optical depth comparisons: One size fits none, J. Geophys. Res.-Atmos., 118, 4748-4766, https://doi.org/10.1002/jgrd.50330, 2013.

Pappalardo, G., Wandinger, U., Mona, L., Hiebsch, A., Mattis, I., Amodeo, A., Ansmann, A., Seifert, P., Linne, H., Apituley, A., Alados Arboledas, L., Balis, D., Chaikovsky, A., D’Amico, G., De Tomasi, F., Freudenthaler, V., Giannakaki, E., Giunta, A., Grigorov, I., Iarlori, M., Madonna, F., Mamouri, R.-E., Nasti, L., Papayannis, A., Pietruczuk, A., Pujadas, M., Rizi, V., Rocadenbosch, F., Russo, F., Schnell, F., Spinelli, N., Wang, X., and Wiegner, M.: EARLINET correlative measurements for CALIPSO: First intercomparison results, J. Geophys. Res.Atmos., 115, D00H19, https://doi.org/10.1029/2009JD012147, 2010.

Prados, A. I., Leptoukh, G., Lynnes, C., Johnson, J., Rui, H., Chen, A., and Husar, R. B.: Access, visualization, and interoperability of air quality remote sensing data sets via the Giovanni online tool, IEEE J. Sel. Top. Appl., 3, 359-370, 2010.

Redemann, J., Vaughan, M. A., Zhang, Q., Shinozuka, Y., Russell, P. B., Livingston, J. M., Kacenelenbogen, M., and Remer, L. A.: The comparison of MODIS-Aqua (C5) and CALIOP (V2 \& V3) aerosol optical depth, Atmos. Chem. Phys., 12, 3025-3043, https://doi.org/10.5194/acp-12-3025-2012, 2012.

Reid, J. S., Kuehen, R. E., Holz, R. E., Eloranta, E. W., Kaku, K. C., Kuang, S., Newchurch, M. J., Thompson, A. M., Trepte, C. R., Zhang, J., Atwood, S. A., Hand, J. L., Holben, B. N., Minnis, P., and Posselt, D. J.: Ground-based High Spectral Resolution Lidar observation of aerosol vertical distribution in the summertime Southeast United States, J. Geophys. Res.-Atmos., 122, 29703004, https://doi.org/10.1002/2016JD025798, 2017.

Rogers, R. R., Vaughan, M. A., Hostetler, C. A., Burton, S. P., Ferrare, R. A., Young, S. A., Hair, J. W., Obland, M. D., Harper, D. B., Cook, A. L., and Winker, D. M.: Looking through the haze: evaluating the CALIPSO level 2 aerosol optical depth using airborne high spectral resolution lidar data, Atmos. Meas. Tech., 7, 4317-4340, https://doi.org/10.5194/amt-7-4317-2014, 2014.

Sayer, A. M., Smirnov, A., Hsu, N. C., and Holben, B. N.: A pure marine aerosol model, for use in remote sensing applications, J. Geophys. Res., 117, D05213, https://doi.org/10.1029/2011JD016689, 2012.

Schuster, G. L., Vaughan, M., MacDonnell, D., Su, W., Winker, D., Dubovik, O., Lapyonok, T., and Trepte, C.: Comparison of CALIPSO aerosol optical depth retrievals to AERONET measurements, and a climatology for the lidar ratio of dust, Atmos. Chem. Phys., 12, 7431-7452, https://doi.org/10.5194/acp12-7431-2012, 2012.
Sekiyama, T. T., Tanaka, T. Y., Shimizu, A., and Miyoshi, T.: Data assimilation of CALIPSO aerosol observations, Atmos. Chem. Phys., 10, 39-49, https://doi.org/10.5194/acp-10-39-2010, 2010.

Shi, Y., Zhang, J., Reid, J. S., Hyer, E. J., Eck, T. F., Holben, B. N., and Kahn, R. A.: A critical examination of spatial biases between MODIS and MISR aerosol products - application for potential AERONET deployment, Atmos. Meas. Tech., 4, 28232836, https://doi.org/10.5194/amt-4-2823-2011, 2011.

Smirnov, A., Holben, B. N., Eck, T. F., Dubovik, O., and Slutsker, I.: Cloud-screening and quality control algorithms for the AERONET database, Remote Sens. Environ., 73, 337-349, 2000.

Smirnov, A., Holben, B. N., Giles, D. M., Slutsker, I., O’Neill, N. T., Eck, T. F., Macke, A., Croot, P., Courcoux, Y., Sakerin, S. M., Smyth, T. J., Zielinski, T., Zibordi, G., Goes, J. I., Harvey, M. J., Quinn, P. K., Nelson, N. B., Radionov, V. F., Duarte, C. M., Losno, R., Sciare, J., Voss, K. J., Kinne, S., Nalli, N. R., Joseph, E., Krishna Moorthy, K., Covert, D. S., Gulev, S. K., Milinevsky, G., Larouche, P., Belanger, S., Horne, E., Chin, M., Remer, L. A., Kahn, R. A., Reid, J. S., Schulz, M., Heald, C. L., Zhang, J., Lapina, K., Kleidman, R. G., Griesfeller, J., Gaitley, B. J., Tan, Q., and Diehl, T. L.: Maritime aerosol network as a component of AERONET - first results and comparison with global aerosol models and satellite retrievals, Atmos. Meas. Tech., 4, 583-597, https://doi.org/10.5194/amt-4-583-2011, 2011.

Stephens, G., Vane, D. G., Boain, R. J., Mace, G. G., Sassen, K., Wang, Z., Illingworth, A. J., O'Connor, E. J., Rossow, W. B., Durden, S. L., Miller, S. D., Austin, R. T., Benedetti, A., and Mitrescu, C.: The CloudSat mission and the A-Train: A new dimension of space-based observations of clouds and precipitation, B. Am. Meteorol. Soc., 83, 1771-1790, 2002.

Tesche, M., Zieger, P., Rastak, N., Charlson, R. J., Glantz, P., Tunved, P., and Hansson, H.-C.: Reconciling aerosol light extinction measurements from spaceborne lidar observations and in situ measurements in the Arctic, Atmos. Chem. Phys., 14, 78697882, https://doi.org/10.5194/acp-14-7869-2014, 2014.

Thorsen, T. J. and Fu, Q.: CALIPSO-inferred aerosol direct radiative effects: Bias estimates using ground-based Raman lidars, J. Geophys. Res.-Atmos., 120, 12209-12220, https://doi.org/10.1002/2015JD024095, 2015.

Toth, T. D., Zhang, J., Campbell, J. R., Reid, J. S., Shi, Y., Johnson, R. S., Smirnov, A., Vaughan, M. A., and Winker, D. M.: Investigating enhanced Aqua MODIS aerosol optical depth retrievals over the mid-to-high latitude Southern Oceans through intercomparison with co-located CALIOP, MAN, and AERONET data sets, J. Geophys. Res.-Atmos., 118, 4700-4714, 2013.

Toth, T. D., Zhang, J., Campbell, J. R., Hyer, E. J., Reid, J. S., Shi, Y., and Westphal, D. L.: Impact of data quality and surface-tocolumn representativeness on the $\mathrm{PM}_{2.5}$ / satellite AOD relationship for the contiguous United States, Atmos. Chem. Phys., 14, 6049-6062, https://doi.org/10.5194/acp-14-6049-2014, 2014.

Toth, T. D., Zhang, J., Campbell, J. R., Reid, J. S., and Vaughan, M. A.: Temporal variability of aerosol optical thickness vertical distribution observed from CALIOP, J. Geophys. Res.-Atmos., 121, 9117-9139, 2016.

Vaughan, M. A., Powell, K. A., Kuehn, R. E., Young, S. A., Winker, D. M., Hostetler, C. A., Hunt, W. H., Liu, Z., McGill, M. J., and Getzewich, B. J.: Fully automated detection of cloud and aerosol 
layers in the CALIPSO lidar measurements, J. Atmos. Ocean. Tech., 26, 2034-2050, 2009.

Vaughan, M., Trepte, C., Winker, D., Avery, M., Campbell, J., Hoff, R., Young, S., Getzewich, B., Tackett, J., and Kar, J.: Adapting CALIPSO Climate Measurements for Near Real Time Analyses and Forecasting, in: Proceedings of the 34th International Symposium on Remote Sensing of Environment, 10-15 April 2011, Sydney, Australia, available at: http://www.calipso.larc.nasa.gov/resources/pdfs/VaughanM_ 211104015final00251.pdf (last access: 20 September 2016), 2011.

Wandinger, U., Hiebsch, A., Mattis, I., Pappalardo, G., Mona, L., and Madonna, F.: Aerosols and clouds: long-term database from spaceborne lidar measurements, Final report, ESTEC, Noordwijk, The Netherlands, 2011.

Winker, D. M., Vaughan, M. A., Omar, A., Hu, Y., Powell, K. A., Liu, Z., Hunt, W. H., and Young, V.: Overview of the CALIPSO mission and CALIOP data processing algorithms, J. Atmos. Ocean. Tech., 26, 2310-2323, 2009.

Winker, D. M., Pelon, J., Coakley Jr., J. A., Ackerman, S. A., Charlson, R. J., Colarco, P. R., Flamant, P., Fu, Q., Hoff, R., Kittaka, C., Kubar, T. L., LeTreut, H., McCormick, M. P., Megie, G., Poole, L., Powell, K., Trepte, C., Vaughan, M. A., and Wielicki, B. A.: The CALIPSO mission: A global 3D view of aerosols and clouds, B. Am. Meteorol. Soc., 91, 1211-1229, https://doi.org/10.1175/2010BAMS3009.1, 2010.
Winker, D. M., Tackett, J. L., Getzewich, B. J., Liu, Z., Vaughan, M. A., and Rogers, R. R.: The global 3-D distribution of tropospheric aerosols as characterized by CALIOP, Atmos. Chem. Phys., 13, 3345-3361, https://doi.org/10.5194/acp-133345-2013, 2013.

Young, S. A. and Vaughan, M. A.: The retrieval of profiles of particulate extinction from Cloud Aerosol Lidar Infrared Pathfinder Satellite Observations (CALIPSO) data: Algorithm description, J. Atmos. Ocean. Tech., 26, 1105-1119, https://doi.org/10.1175/2008JTECHA1221.1, 2009.

Yu, H., Chin, M., Winker, D. M., Omar, A. H., Liu, Z., Kittaka, C., and Diehl, T.: Global view of aerosol vertical distributions from CALIPSO lidar measurements and GOCART simulations: Regional and seasonal variations, J. Geophys. Res.-Atmos., 115, D00H30, https://doi.org/10.1029/2009JD013364, 2010.

Zhang, J., Campbell, J. R., Reid, J. S., Westphal, D. L., Baker, N. L., Campbell, W. F., and Hyer, E. J.: Evaluating the impact of assimilating CALIOP-derived aerosol extinction profiles on a global mass transport model, Geophys. Res. Lett., 38, L14801, https://doi.org/10.1029/2011GL047737, 2011.

Zhang, J., Campbell, J. R., Hyer, E. J., Reid, J. S., Westphal, D. L., and Johnson, R. S.: Evaluating the impact of multisensory data assimilation on a global aerosol particle transport model, J. Geophys. Res.-Atmos., 119, 4674-4689, https://doi.org/10.1002/2013JD020975, 2014. 